UDC 621

LBC 31.15

\title{
THE USE OF HEAT EXHAUST VENTILATION IN POULTRY FARMS
}

\author{
Aleksey V. Sklyar \\ OOO "Big Dutchman", Moscow, Russian Federation; \\ Big Dutchman AG (holding) Auf der Lage, Vechta, Germany \\ Viktor I. Minaev \\ Open Society 'Cherepovets broiler', Vologodskaya oblast', Cherepovetskij rajon, the village of Klimovskoe \\ Valery V. Mokhov \\ Open Society 'Cherepovets broiler', Vologodskaya oblast', Cherepovetskij rajon, the village of Klimovskoe \\ Margarita V. Postnova \\ Volgograd State University, Volgograd, Russian Federation
}

\begin{abstract}
Modern poultry farming is associated with emissions of a significant amount of heat into the atmosphere and from the position of the Kyoto Protocol. The same time, energy is a significant component in the cost of eggs, poultry meat, and all food products from them. The original design of recuperative heat exchangers to minimize aerodynamic drag allowing exhaust air to remove axial fans on the inflow in this case are inevitable radial fans, taking into account the use of the heater. In addition to heat recovery, this vent structure can work both at vacuum and at excessive pressure in the poultry house, for example, in the starting period for broilers. The heat exchanger of the proposed design was tested in the pilot poultry house of OS 'Cherepovets broiler', where the installation showed high efficiency by a third to reduce the annual heat consumption compared to other poultry farms located in a similar climatic zone.
\end{abstract}

Key words: poultry farms, heat, heat exchangers, ventilation constructions.

УДК 536

ББК 40.77

\section{ИСПОЛЬЗОВАНИЕ ТЕПЛА ВЫТЯЖНОЙ ВЕНТИЛЯЦИИ ПТИЧНИКОВ}

\section{Алексей Владимирович Скляр}

ООО «Биг Дачмен», г. Москва, Российская Федерация; Big Dutchman AG (холдинг), Vechta, Германия

\section{Виктор Иванович Минаев}

ОАО «Череповецкий Бройлер», Вологодская область, Череповецкий район, деревня Климовское

\section{Валерий Владимирович Мохов}

ОАО «Череповецкий Бройлер», Вологодская область, Череповецкий район, деревня Климовское

\section{Маргарита Викторовна Постнова}

Волгоградский государственный университет, г. Волгоград, Российская Федерация

Аннотация. Современное птицеводство связано с выбросами в атмосферу значительного количества тепла и с позиции Киотского протокола, энергетика является значимой составляющей в себестоимости яиц, 
птичьего мяса и всех пищевых изделий из них. Предложены оригинальные конструкции рекуперативных теплоутилизаторов позволяющих минимизировать аэродинамические сопротивления позволяющие отработанный воздух удалять аксиальными вентиляторами, на притоке в этом случае неизбежны радиальные вентиляторы, учитывая использование калорифера. Плюс такой вентиляционной структуры помимо утилизации тепла еще и в том, что она может работать как на разрежении, так и на избыточном давлении в птичнике, например, в стартовый период для бройлеров. Теплоутилизатор предлагаемой конструкции тестировался в пилотном птичнике ЗАО «Череповецкий бройлер», где установка показала высокую эффективность работы на треть снизить годовой расход тепла по сравнению с другими птицеводческими хозяйствами, расположенными в аналогичной климатической зоне.

Ключевые слова: птицеводческие хозяйства, теплоутилизаторы, конструкции, вентиляция, тепло.

Производя 4,3 млн тонн мяса птицы и до 44 млрд яиц в год, птицеводческие хозяйства (ПХ) РФ «попутно обогревают» атмосферу только бройлерные фабрики выбрасывают из птичников за отопительный сезон более трети миллиарда Гкал тепла [1; 2; 3; 4]. Помимо того, что сброс отработанного теплого воздуха в атмосферу - это позиция Киотского протокола, энергетика является значимой составляющей в себестоимости яиц, птичьего мяса и всех пищевых изделий из них. Это естественно, так как Россия самая высокоширотная страна с развитым промышленным птицеводством и в настоящее время с постоянно увеличивающимся числом крестьянскофермерских птицеводческих хозяйств [5]. Анализ уравнения теплового баланса, например, птичника для откорма бройлеров на глубокой подстилке $96 \times 18 \times 3$ м (условно, для широты г. Киров) - Qотопит. = Qнагр. притока $+\mathrm{Q}$ огражд. пт-ка. + Q испар. - Q тепл. птицы показывает, что наибольшие затраты тепла идут на подогрев свежего воздуха: Q нагр. притока $=\mathrm{L} \times$ Үв $\times$ Zв $\times($ tв-tн $)=30800 \mathrm{~m}^{3} / \mathrm{ч} \times$

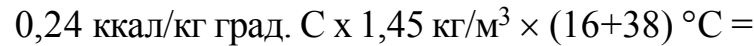
598752 ккал/ч (в формуле: L - объем притока, Үв - теплоемкость и Zв - плотность воздуха, tв, tн - его температура внутри и вне птичника). По расчету затраты тепла на подогрев притока в 6 раз больше тепловых потерь птичника (106 154 ккал/ч) и потому, не умаляя роли утепления строений, актуальнее изза экологических соображений и возможности сохранения тепла - применять рекуперативные теплоутилизаторы (ТУ). Их внедрение будет массовым при условии, если они обеспечат высокий коэффициент полезного действия (КПД) по теплу (с исключением обмерзания в период пиковых холодов), простоту конструкции, надежность в работе и мало затратный технический сервис (ЕTO, TO-1, ТО-2, ТР), а также выполнение быстрой и качественной санации в профессиональные перерывы (частично быстроразборный ТУ), с окупаемостью в течение 1-2 отопительных сезонов. т.к. подобрать серийный ТУ отвечающий всему перечисленному непросто, на базе $3 \mathrm{AO}$ «Череповецкий бройлер» были выполнены расчеты и сделаны пластинчатые ТУ оригинальной конструкции, соответствовавшие этим требованиям. При расчетах определялись: среднелогарифмические температурные потенциалы на входе и выходе из аппарата, тепломощности по вытяжке и притоку, расход теплого и холодного теплоосителей $\left(\mathrm{G}_{\text {гор/ }} \mathrm{G}_{\text {хол }}=258\right.$ 000/217 580ккал/ч), соотношение числа каналов греющей и нагреваемой среды, поверхности теплообмена, скорости воздушных потоков на притоке (до 5 м/с), вытяжке (до $10 \mathrm{~m} / \mathrm{c}$ ) и пр.

В конструктивном плане ТУ представляет параллелепипед размерами в плане (Д × Ш) под стандартные оцинкованные металлолисты $2500 \times 1250(2000 \times 1000)$ мм, толщиной до 0,7 мм. По высоте он набирается по потребной мощности в пределах $1720 \ldots 2540$ мм. Каркас ТУ выполнен из уголка $50 \times 50 \times 4$ мм. В прямоугольник рамы основания ТУ размерами $2500 \times 1250$ мм по длинной стороне через 625 мм ввариваются три перемычки (длиной по 1250 мм). На эту основу укладывается первый оцинкованный металлолист. К уголкам рамы его привинчивают саморезами через планки (квадратные в сечении $40 \times 40$ мм). На планки первого листа кладут второй лист и поверх него размещают такие же планки и аналогично саморезами закрепляют второй лист с его планками (свинчивая их с планками первого листа). Отличие здесь только в том, что во всех соседних слоях (ще- 


\section{МАТЕРИАЛЫ КОНФЕРЕНЦИИ}

левых воздуховодах) планки размещают поразному: если в нечетных слоях (например, в первом) планки укладываются по длинной стороне параллелепипеда, то во всех четных начиная со второго - только по короткой и т. д. В первом случае лист к уголкам прижимают 3 планки - по краям и по его центру (где саморезы ввинчиваются в три перемычки и по краям) - получаются 2 щелевых воздуховода притока с площадью сечения по $565 \times 40$ мм (при ширине листа 1000 мм - $440 \times 39$ мм). В четных слоях планки скрепляют с перемычками и короткими крайними уголками. Площади сечений 4 щелевых воздуховодов одного слоя и ТУ в целом на вытяжке вдвое больше приточных (2..3 против $\left.1,0 \ldots 1,5 \mathrm{~m}^{2}\right)$ и, учитывая еще и в 2 раза меньшую длину воздуховода - вся эта минимизация аэродинамических сопротивлений позволила отработанный воздух удалять аксиальными вентиляторами, на притоке в этом случае неизбежны радиальные вентиляторы, учитывая использование калорифера, ТУ и протяженных воздухозаборных и распределительных воздуховодов. Плюс такой вентструктуры помимо утилизации тепла еще и в том, что она может работать как на разрежении, так и на избыточном давлении в птичнике, например, в стартовый период для бройлеров. Планки могут быть деревянными (с гидрофобной защитой), пластиковыми и т. п., кожуха-переходники (к ВО-12, к КСк, от приточного воздуховода) выполняются из оцинкованного листа (толщина 0,7 мм) как коллекторный и наружный воздуховоды. ТУ рассчитан на быстрое качественное выполнение санаций (только с отсоединением притока): параллелепипед устанавливается с поперечными и продольным наклонами 3-5 гр. к горизонту (для стока воды при мойке), переходный кожух от притока к ТУ съемный. Это позволяет выполнять его эффективную мойку-гидроочистку высоконапорными (до 5-7 Мпа) установками, проводить влажные дезинфекции и газовую обработку.

Теплоутилизатор рассмотренной конструкции тестировался в одном («пилотном») птичнике этого хозяйства, где установка по- казала высокую эффективность работы: при температуре наружного воздуха $-15^{\circ} \mathrm{C}$ на калорифер догрева подавался воздушный поток с температурой $0{ }^{\circ} \mathrm{C}$ и при этом, строительство такого оригинального ТУ окупалось всего за один отопительный сезон. Это позволило хозяйству, используя лишь средства, отчисляемые на амортизацию оборудования, за несколько лет реконструировать систему вентиляции-обогрева под ТУ и утилизировать тепло в $81 \%$ птичников ЗАО «Череповецкий бройлер» (45 зданий). Масштабное переоборудование дало возможность хозяйству на треть снизить годовой расход тепла (79 тыс. Гкал вместо 119,7 т Гкал), в сравнении с бройлерными фабриками сопоставимой мощности (13,5-15 т т/год), расположенными в аналогичной климатической зоне (птицефабрики Шекснинская, Р-Высоцкая и др.). По масштабам только бройлерного производства РФ годовое уменьшение тепловых выбросов (Киотский протокол) составит 8,6 млн Гкал, потребление газа снизится на 1,075 млрд м ${ }^{3}$.

\section{СПИСОК ЛИТЕРАТУРЫ}

1. Горобец, В. Г. Компьютерное математическое моделирование процессов и массопереноса при вентиляции воздуха в птицеводческих помещениях / В. Г. Горобец, В. И. Троханяк // Вестник ВИЭСХ. - 2015. - № 4 (21). - С. 85-90.

2. Искандерова, А. Д. Совершенствование системы вентиляции птичника / А. Д. Искандерова // Аграрная наука. - 2014. - № 5.- С. 27-28.

3. Кравцов, Д. С. Разработка энергосберегающей системы вентиляции птичника / Д. С. Кравцов // Научно-образовательный потенциал молодежи в решении актуальных проблем XXI века. 2017. - № 6. - С. 241-245.

4. Салеева, И. И. Состав воздуха и продуктивность бройлеров / И. И. Салеева, А. И. Иванов, А. В. Бахарев // Животноводство России. - 2017. № 53. - C. 19-22.

5. Троханяк, В. И. Моделирование температурного поля с помощью Matlab Simulink системы микроклимата в птичнике в зимний период года / В. И. Троханяк // APRIORI. Серия: Естественные и технические науки. - 2016. - № 6. - С. 26. 


\section{Information about the Authors}

Aleksey V. Sklyar, Candidate of Sciences (Agriculture), Official agent, Big Dutchman AG (холдинг) Auf der Lage 249377 Vechta-Calveslage Postfach 116349360 Vechta, Germany, vsklar41@mail.ru.

Viktor I. Minaev, General Birector, Open Society 'Cherepovets broiler', Tsentral'naya St., 25, 162699, Vologodskaya oblast', Cherepovetskiy rayon, the village of Klimovskoe, Russian Federation, info@sheksna.com.

Valery V. Mokhov, Chief Engineer, Open Society 'Cherepovets broiler', Tsentral'naya St., 25, 162699, Vologodskaya oblast', Cherepovetskiy rayon, the village of Klimovskoe, Russian Federation, vsklar41@mail.ru.

Margarita V. Postnova, Doctor of Biological Sciences, Chief, Department of Bioengineering and Bioinformatics, Volgograd State University, Prosp. Universitetskiy, 100, 400062 Volgograd, Russian Federation, postnova@volsu.ru.

\section{Информация об авторах}

Алексей Владимирович Скляр, кандидат сельскохозяйственных наук, представитель, OОО «Биг Дачмен», г. Москва, Российская Федерация; Big Dutchman AG (холдинг) Auf der Lage 249377 Vechta-Calveslage Postfach 116349360 Vechta, Германия, vsklar41@mail.ru.

Виктор Иванович Минаев, генеральный директор ОАО «Череповецкий Бройлер», ул. Центральная, 25, 162699, Вологодская область, Череповецкий район, деревня Климовское, Российская Федерация, info@sheksna.com.

Валерий Владимирович Мохов, главный инженер ОАО «Череповецкий Бройлер», ул. Центральная, 25, 162699, Вологодская область, Череповецкий район, деревня Климовское, Российская Федерация, vsklar41@mail.ru.

Маргарита Викторовна Постнова, доктор биологических наук, старший научный сотрудник, заведующая кафедрой биоинженерии и биоинформатики, Волгоградский государственный университет, пр. Университетский, 100, 400062 г. Волгоград, Российская Федерация, postnova@volsu.ru. 